Sharif University of Technology
Scientia Iranica
SCIENTIA
IRANICA
http://scientiairanica.sharif.edu

\title{
Flexural and shear strengthening of RC beams with NSM technique and manually made CFRP bars
}

\author{
M.K. Sharbatdar* and M. Jaberi \\ Faculty of Civil Engineering, Semnan University, Semnan, P.O. Box 3513119111, Iran. \\ Received 14 September 2016; received in revised form 5 January 2017; accepted 11 March 2017
}

\section{KEYWORDS}

Beams;

Shear;

Flexural

strengthening;

Composite materials;

Numerical;

NSM.

\begin{abstract}
In this paper, the efficiency of NSM method for both flexural and shear strengthening of RC beams was examined by applying an innovative manually made CFRP bar (MMFRP) as an alternative reinforcement composite material through experimental and numerical investigation. The experimental program consists of three inverted T-section $\mathrm{RC}$ flexural-dominated beams and three rectangular section RC shear-dominated beams involving parameters of length, anchoring of MMFRP bars, and their inclination to the beams' longitudinal axis. The structural performances of the tested beams and the FiniteElement (FE) modelling approach, including modes of failure, load-deflection response, and ultimate load capacity, were presented and discussed. Test results indicated that using the proposed MMFRP bars significantly improved the flexural resistance and shear capacity of deficient concrete beams. Furthermore, a reduction in the crack width along with an increase in the quantity and propagation of new cracks was observed in strengthened beams, compared to control beams.

(C) 2018 Sharif University of Technology. All rights reserved.
\end{abstract}

\section{Introduction}

A large number of existing buildings and structures require strengthening due to factors such as deterioration and construction or design faults. Recently, Fiber Reinforced Polymer (FRP) has been used extensively as an alternative reinforcement material to steel to strengthen and repair existing concrete structures [1-3]. To optimize the utilization of FRP materials, Near Surface Mounted (NSM) reinforcement has been recently introduced as a promising method to strengthen the reinforced concrete members [4,5]. Design guidelines for this technique are currently under consideration by the ACI Committee 440 [6]. A state-of-the-art review of existing experimental data regarding concrete

*. Corresponding author. Tel./Fax: +98 2313354121 E-mail addresses: msharbatdar@semnan.ac.ir (M.K. Sharbatdar); 2005.mostafa@gmail.com (M. Jaberi)

doi: $10.24200 /$ sci.2017.4207 beams, slabs, and columns strengthened with NSM FRP reinforcement was presented [7]. The obtained results indicated that the NSM reinforcement improved the ultimate load, post-cracking stiffness, and possible failure modes of strengthened beams. Using NSM FRP reinforcement is also effective in improving the shear capacity of RC beams, and the NSM reinforcement leads to an increase in shear strength which is as high as $106 \%$ in the absence of steel stirrups; thus, two different failure modes would be identified [8]. A series of RC T-beams were tested experimentally with the CFRP, and steel strips were carefully aligned and spaced [9]. A number of beams were tested to analyze the influence of the test parameters' structural behaviors and failure mode and show an increase in shear capacity ranging from $22 \%$ to $44 \%$ [10]. Anwarul Islam [11] studied the shear strengthening of four concrete beams with NSM CFRP bars and reported an increase in shear capacity, ranging from $17 \%$ to $25 \%$ over the control beam. Researchers investigated the effectiveness of shear and flexural strengthening of 
beams reinforced with NSM-CFRP strips, which were Externally Bonded Reinforcing (EBR) with CFRP strips. They concluded that the NSM and EBR strips form a good combination to resist the applied load. Moreover, the test results revealed that sheardeficient beams might well be strengthened by the externally applied FRP strips $[12,13]$. Recently, the efficiency of the NSM technique using MMFRP rods for shear strengthening of RC beams was investigated [14], revealing that the MMFRP (Manually-Made FRP) rods effectively enhanced the shear capacity of tested beams. Moreover, efficiency of the NSM technique was tested on RC columns' flexural strengthening and reinforced concrete beams with low concrete strength, showing that the proposed strengthening technique is feasible and effective for improving the flexural capacity and energy dissipation capacities $[15,16]$.

\section{Research highlights}

This study evaluates the effectiveness of the proposed Manually Made FRP bar (MMFRP) for flexural and shear strengthening of six RC beams using the NSM method. MMFRP bars were manually made in the laboratory and hooked at the end for anchoring in concrete. The effect of MMFRP bars on the behavior of strengthened beams was examined through experimental and numerical study. Using hand-made FRP bars in lab in case of un-availability of pre-fabricated bars particularly with made hooks is one of highlights in this research.

\section{Experimental program}

To examine the general performance of the proposed MMFRP bars in NSM strengthening technique, two ex- perimental groups were selected: a group of $\mathrm{RC}$ beams strengthened in bending and a group of RC beams strengthened in shear. To simulate a real strengthening situation, flexural and shear beams should have a limited amount of longitudinal and shear reinforcement, respectively.

\subsection{Material properties}

The average compressive strengths of concrete cylinders ( 150 by $300 \mathrm{~mm}$ ) while testing were approximately $22.1 \mathrm{MPa}$ and 24.3 MPa for shear and flexural beams, respectively. Table 1 shows the main properties of the steel bars used in the experimental program. The mechanical properties of steel bars were obtained from the tensile test. A new type of circular CFRP bars, called MMFRP, was manually made in the laboratory by wrapping FRP sheets around a wooden rod and hooking the ends to anchor the concrete. These bars are made up of three ingredients, i.e. dry unidirectional $0.11 \mathrm{~mm}$ thickness carbon fiber sheet, epoxy resin, and round $10 \mathrm{~mm}$ diameter special wooden bar, based on wet lay-up technique [6] shown in Figure 1. A special wooden bar is harder than a regular wood and can keep FRP bars during casting and manufac-

Table 1. Mechanical properties of the steel bars.

\begin{tabular}{ccc}
\hline $\begin{array}{c}\text { Bar } \\
\text { diameter } \\
(\mathbf{m m})\end{array}$ & $\begin{array}{c}\text { Yielding } \\
\text { stress } \\
(\mathbf{M P a})\end{array}$ & $\begin{array}{c}\text { Ultimate } \\
\text { stress } \\
(\mathbf{M P a})\end{array}$ \\
\hline 6 & 190 & 230 \\
8 & 545 & 575 \\
10 & 335 & 370 \\
14 & 430 & 470 \\
18 & 480 & 510 \\
\hline
\end{tabular}

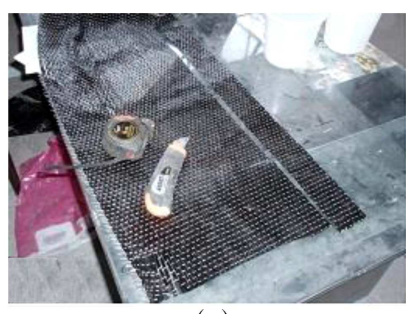

(a)

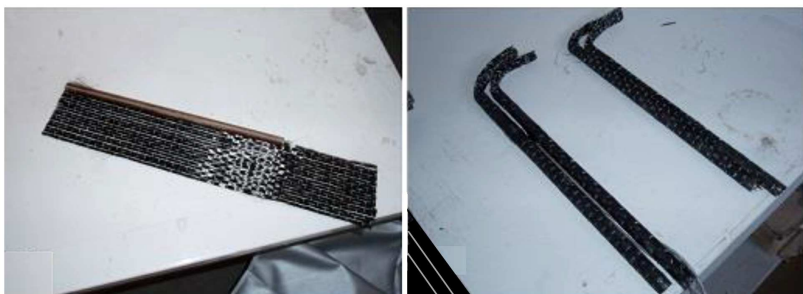

(d)

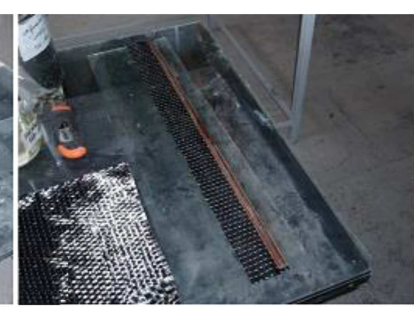

(b)

(e)

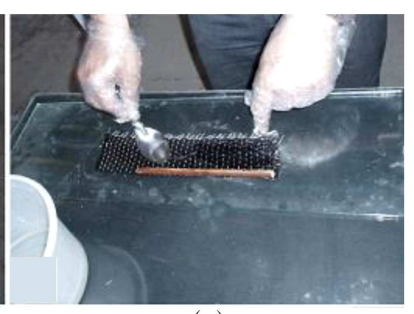

(c)

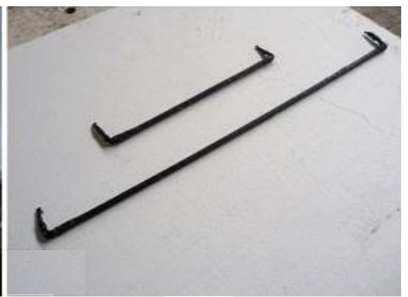

(f)

Figure 1. Manufacturing of MMFRP bars: (a) Cutting a strip from the FRP roll, (b) placing the wooden bar on the FRP strip, (c) uniform saturating of FRP strip by resin and wrapping around the wooden bar, (d) stirrup strip, (e) hooked MMFRP stirrups, and (f) hooked MMFRP bars. 
turing. Moreover, the maximum tensile strength of this wooden bar is $60 \mathrm{MPa}$ tested by tension testing machine. The manufacturer's values of tensile strength, elastic modulus, and ultimate tensile strain of CFRP sheets were equal to $3550 \mathrm{MPa}, 235 \mathrm{GPa}$, and $1.5 \%$, respectively. The length of the FRP strip equals to that of the bar, and $70 \mathrm{~mm}$ of its width (calculated based on the required design of cross-sectional area) was cut from the FRP roll (Figure 1(a)) and wrapped around the wooden bar (Figure 1(b)); then, it was mixed and saturated with two-component low viscosity epoxy resin (Figure 1(c)). Furthermore, it was placed under a condition with proper temperature for five days to be cured. The diameter of the manufactured bars was $12 \pm 1 \mathrm{~mm}$ (around $10 \mathrm{~mm}$ diameter of special wooden bar) with $8 \mathrm{~mm}^{2}$ FRP cross-sectional area. FRP strip length was calculated by adding the anchored length to the bar length to prepare hooks (Figure 1(d)). To prevent stress concentration, the fibers were rounded to $10 \mathrm{~mm}$ radius of curvature, as shown in Figure 1(e) and (f). It was evidenced that the proposed manufacturing procedure is inexpensive, feasible, and easy to apply. The mechanical properties of MMFRP bars were determined through tension between the coupon test shown in Figure 2 with the procedure specified based on CSA standard S806 [17,18]. The steel tubes were filled with specially mixed grout consisting of epoxy resin, hardener, and fine sand. A tension-testing machine was used for testing three specimens, giving the average modulus

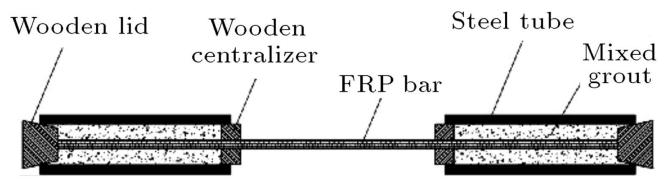

(a)

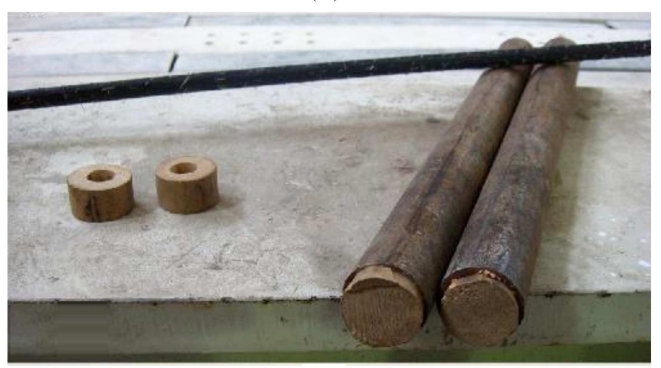

(b)

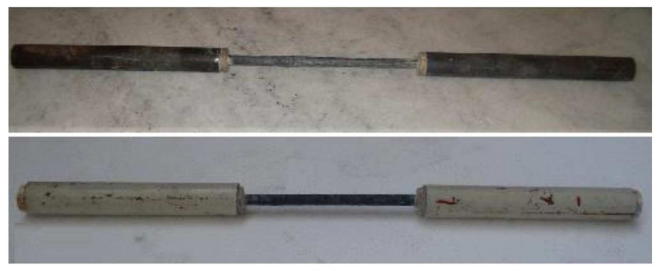

(c)

Figure 2. Details of coupon specimens: (a) Schematic view of specimens, (b) preparation of specimens, and (c) specimens before tensile test.
Table 2. Mechanical properties of Manually Made FRP bars (MMFRP).

\begin{tabular}{cccc}
\hline $\begin{array}{c}\text { FRP cross } \\
\text { sectional } \\
\begin{array}{c}\text { area } \\
\left(\mathbf{m m}^{2}\right)\end{array}\end{array}$ & $\begin{array}{c}\text { Modulus of } \\
\text { elasticity } \\
(\text { GPa })\end{array}$ & $\begin{array}{c}\text { Tensile } \\
\text { strength } \\
(\mathbf{M P a})\end{array}$ & $\begin{array}{c}\text { Diameter of } \\
\text { fabricated } \\
\text { bars } \\
(\mathbf{m m})\end{array}$ \\
\hline 8.0 & $220-230$ & 1920 & $12 \pm 1$ \\
\hline
\end{tabular}

of elasticity of $225 \mathrm{GPa}$ and mechanical properties as given in Table 2 .

\subsection{Specimen characteristics}

Geometry, reinforcement arrangements, loading, and supporting conditions of flexural and shear specimens are represented in Figure 3. The flexural series shown in Figure 3(a) is composed of a total of three inverted T-section beams with an overall length of $1800 \mathrm{~mm}$, clear span of $1600 \mathrm{~mm}$, and height of $300 \mathrm{~mm}$, with diameters of $14 \mathrm{~mm}$ and $10 \mathrm{~mm}$ as longitudinal and $8 \mathrm{~mm}$ as stirrup steel bars. The inverted T-section configuration was selected to represent the typical integrated beam-slab construction in the negative moment region. The beams were simply supported at both ends and were loaded under two-point symmetrical bending. Three shear specimens, shown in Figure 3(b), with a rectangular section and an overall length of $1300 \mathrm{~mm}$, clear span of $1100 \mathrm{~mm}$, and depth of $220 \mathrm{~mm}$, were constructed with 18,10 , and $6 \mathrm{~mm}$ steel bars and tested simply by the support ends under a concentrated load applied at the beams mid-span.

\subsection{Strengthening layout}

In flexural strengthening series, B1 beam as a control specimen was tested without considering strength, and B2 and B3 specimens were strengthened with two MMFRP bars beneath the beam flange. The type of groove filling epoxy, dimension of grooves, and NSM reinforcement spacing were kept constant for strengthened specimens; however, the embedment lengths and the MMFRP bars anchorage were considered as test variables. Beam B2 was strengthened through the medium of two FRP bars with embedment lengths of $1500 \mathrm{~mm}$ (equal to $85 \%$ of the total length) and enough development length for each FRP bar without any probable debonding. If there is not enough development length for tensile bars to decrease the bar costs and use shorter lengths, using hook would be the substitute alternative to provide the required bonding strength. Therefore, beam B3 was strengthened via two FRP bars with shorter and different embedment lengths as well as use of hooks given in Table 3 and shown in Figure 4(a). One bar length is $900 \mathrm{~mm}$, equal to about $50 \%$ of the total length, while the other one is $450 \mathrm{~mm}$, equal to about $25 \%$ of the total length. The hook length of MMFRP bars was $70 \mathrm{~mm}$ with angle of $90^{\circ}$. Since only two strengthening bars are used 

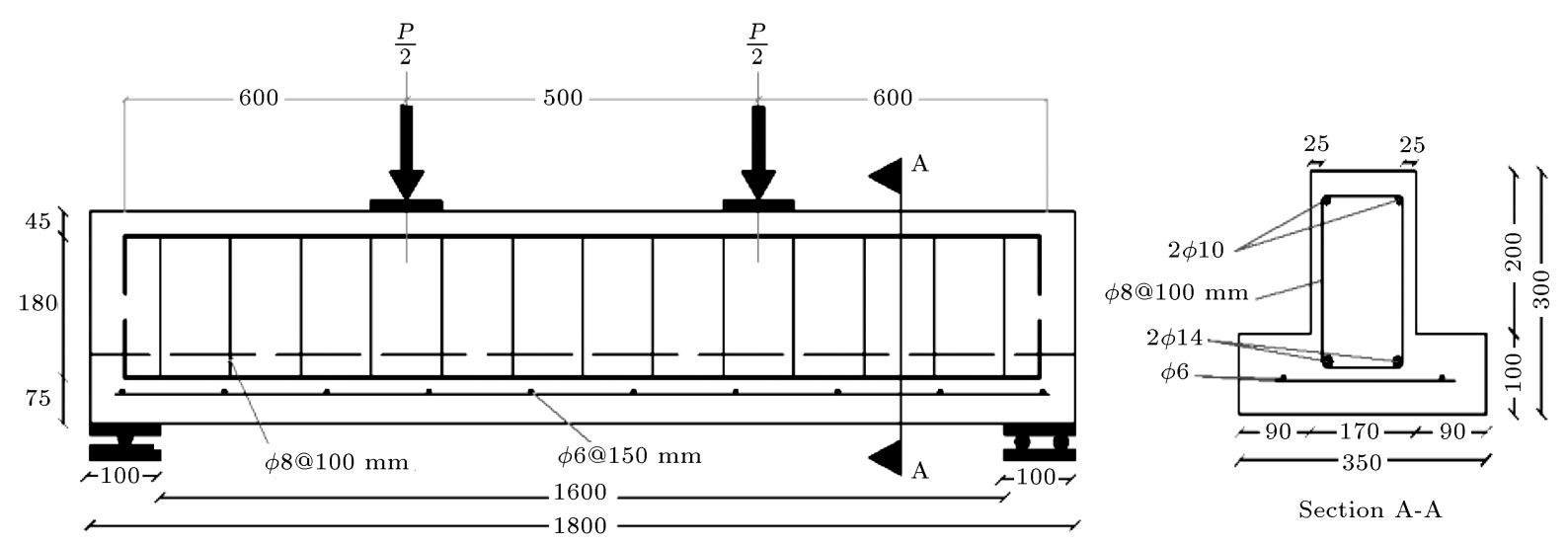

(a)

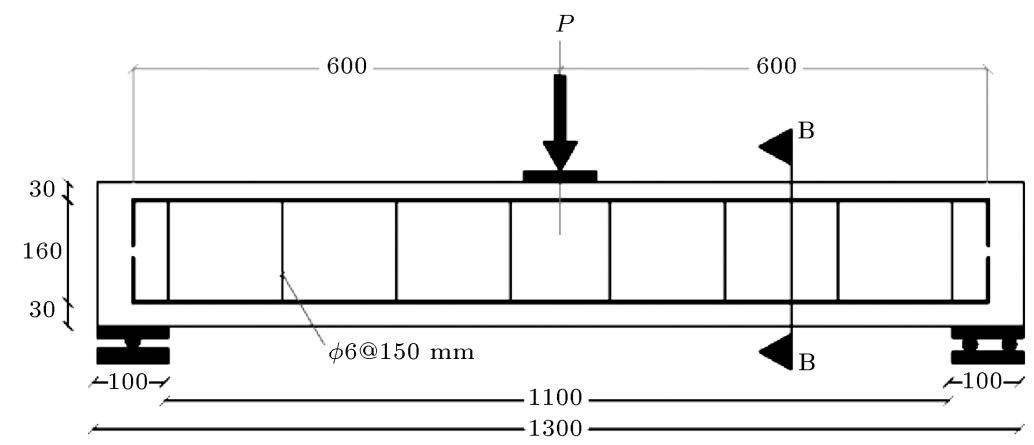

(b)

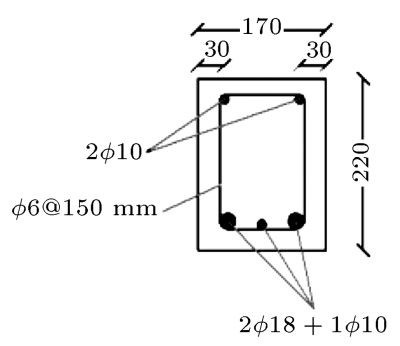

Section B-B

Figure 3. Test setup, beam details, and cross-section of beams: (a) Flexural beams, and (b) shear beams (all dimensions are in millimeters).

Table 3. Test specimens for flexural beams.

\begin{tabular}{cccc}
\hline Beam & Strengthening system & $\begin{array}{c}\text { FRP cross } \\
\text { sectional area } \\
\left(\mathbf{m m}^{\mathbf{2}}\right)\end{array}$ & $\begin{array}{c}\text { Embedment } \\
\text { length } \\
(\mathbf{m m})\end{array}$ \\
\hline B1 & None (control beam) & - & - \\
B2 & 2 NSM MMFRP bar & $8.0 \mathbf{m m}^{2}$ & 1500 \\
B3 & 2 NSM MMFRP bar & $8.0 \mathbf{m m}^{2}$ & 450 and 900 (hooked) \\
\hline
\end{tabular}

in beam B3, it appears that the beam may represent unsymmetrical behavior; however, the overall behavior and recorded strain gauges of steel longitudinal bars show that there is no negative effect of this FRP bar arrangement on beam symmetric behavior.

In shear strengthening series, beam $\mathrm{S} 1$, as the control beam, was not strengthened, whereas those two other beams, S2 and S3, were strengthened through the medium of two MMFRP bars with a $150-\mathrm{mm}$ space on both sides of the beams. FRP cross-sectional area of each bar was $8 \mathrm{~mm}^{2}$. The types of groove filling epoxy and dimension of grooves were kept constant for the strengthened specimens. The inclination of MMFRP bars towards the beams' longitudinal axis was considered a variable. Two different angles were selected: 900 and 450 for beams S2 and S3, respectively. To enhance the bond properties, MMFRP bars were hooked at one end with $10 \mathrm{~mm}$ radius of curvature and angle of 900, and anchored on the top surface of beams. Shear strengthening program is given in Table 4 and shown in Figure 4(b).

As shown in Figure 5, the strengthening procedure of RC beams consists of cutting slits with a nominal size of $18 \mathrm{~mm}$ into the soffit cover of flexural beams and a two-sided cover of shear beams, cleaning grooves by compressed air for removing debris and dust, attaching strain gauges to bars at the critical locations before placing them into grooves, mixing (in a 3:1 weight ratio with resin and hardener) and pouring two-component high viscosity epoxy components as a mortar binder (modulus of elasticity of $12.8 \mathrm{GPa}$ and an average tensile strength of $4.0 \mathrm{MPa}$ ) into the grooves, inserting the bars inside the grooves and completely covering them with epoxy and leveling surface, and finally leaving the specimens at room temperature for at least five days to ensure 
Table 4. Test specimens for shear beams.

\begin{tabular}{ccccc}
\hline Beam & Strengthening system & $\begin{array}{c}\text { FRP cross } \\
\text { sectional area } \\
\left(\mathbf{m m}^{\mathbf{2}}\right)\end{array}$ & $\begin{array}{c}\text { Angle of } \\
\text { MMFRP bars to } \\
\text { the longitudinal } \\
\text { axis of beam } \\
\text { (deg.) }\end{array}$ & $\begin{array}{c}\text { Spacing of } \\
\text { MMFRP bars } \\
(\mathbf{m m})\end{array}$ \\
\hline S1 & None (control beam) & - & - & - \\
S2 & Hooked NSM MMFRP bar & $8.0 \mathrm{~mm}^{2}$ & 90 & $150 \mathrm{~mm}$ \\
S3 & Hooked NSM MMFRP bar & $8.0 \mathrm{~mm}^{2}$ & 45 & $150 \mathrm{~mm}$ \\
\hline
\end{tabular}
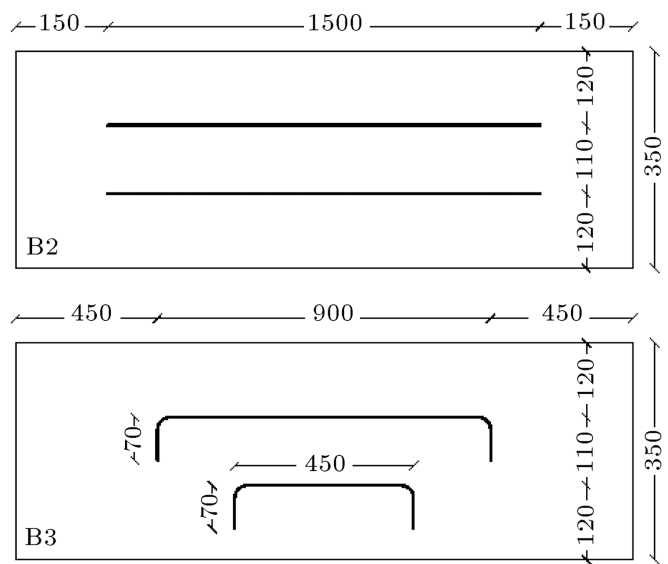

(a)
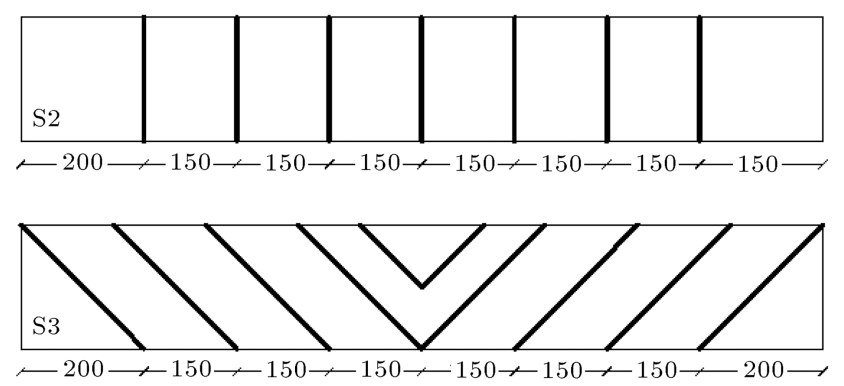

(b)

Figure 4. NSM Strengthening technique: (a) Flexural $\mathrm{RC}$ beams, and (b) shear RC beams (dimensions in $\mathrm{mm}$ ).

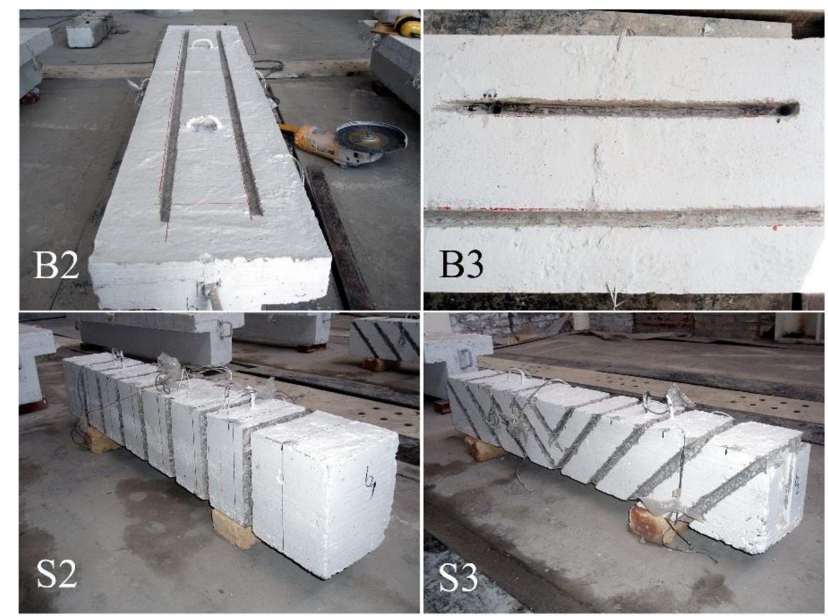

Figure 5. Cutting the groove of RC beams. that the epoxy reaches its full mechanical properties.

\subsection{Test setup and instrumentation}

Prior to beams casting, strain gauges were attached to different positions (at maximum moment positions and out of that point, the maximum shear position, and the other points) on the steel reinforcement. Eight strain gauges were used for each flexural beams, and 12 to 14 strain gauges were used for shear beams, as shown in Figure 6. The beams were instrumented with two LVDTs at mid-span, on both sides of the beam soffit, to monitor the average of deflection. Loads, displacements, and strains were all recorded by an electronic data logger system, and cracks' propagation was marked.

\section{Test results and discussion}

\subsection{Flexural beams}

The load-deflection behavior of the flexural beams is shown in Figure 7 with its summarized results given in Table 5. After cracking and prior to the yielding points of the internal steel tensile reinforcements (the point in which rapid changes of curve slope occur) of B2 and B3 beams at 130 and $125 \mathrm{kN}$, respectively, the flexural behavior for all strengthened beams is almost similar to the unstrengthened beam. This behavior indicates that these bars do not contribute to increasing the stiffness in the elastic linear range prior to concrete cracking capacity equal to $30 \mathrm{kN}$, as shown in Figure 7 . However, after yielding the tensile reinforcements, the flexural stiffness and strength of the NSM beams, compared to the control beam, were significantly improved. The control beam, B1, behaves like a conventional flexural beam and fails due to yielding tensile reinforcements and crushing the concrete, as shown in Figure 8(a). Beam B2 exhibited linear behavior at the point of cracking, followed by a nonlinear behavior until yielding the steel reinforcement occurred. After yielding the steel reinforcement, an increase in the applied load was observed up until when shear failure occurred after debonding observed at one end of the beam at the cutoff section of NSM MMFRP bars, as shown in Figure 8(b) and (c). Thereafter, the load dropped to a 

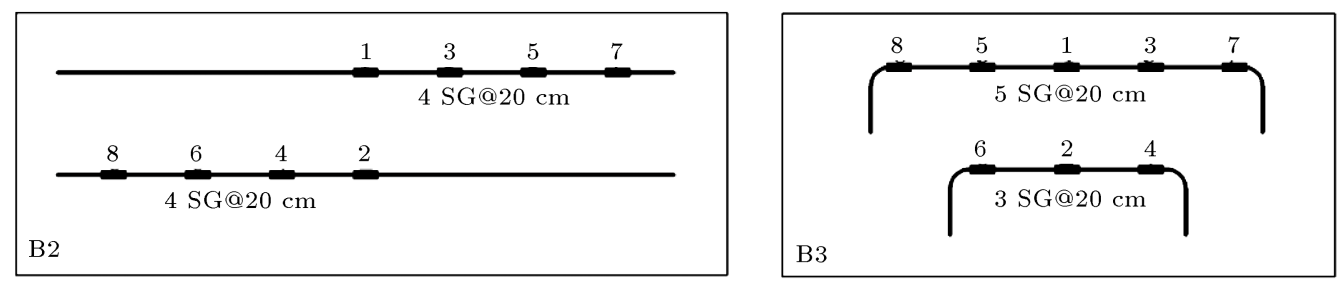

(a)
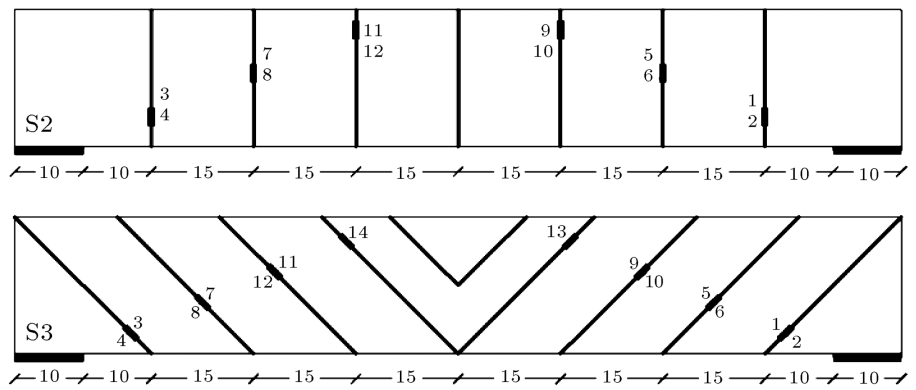

(b)

Figure 6. Strain gauge positions on FRP bars of tested specimens: (a) Flexural beam specimens, and (b) shear beam specimens.

Table 5. Experimental results of flexural beams.

\begin{tabular}{|c|c|c|c|c|c|c|c|c|c|}
\hline Beam & $\begin{array}{c}P_{c r} \\
(k N)\end{array}$ & $\begin{array}{c}\Delta_{c r} \\
(\mathbf{m m})\end{array}$ & $\begin{array}{c}\boldsymbol{P}_{\boldsymbol{Y}} \\
(\mathrm{kN})\end{array}$ & $\begin{array}{c}\Delta_{y} \\
(\mathbf{m m})\end{array}$ & $\begin{array}{c}\boldsymbol{P}_{U} \\
(\mathbf{k N})\end{array}$ & $\begin{array}{c}\Delta_{u} \\
(\mathbf{m m})\end{array}$ & $\begin{array}{c}\varepsilon_{u} \\
(\%)\end{array}$ & $\begin{array}{l}\text { Increase } \\
\text { in } P_{U} \\
\quad(\%)\end{array}$ & Failure mode \\
\hline B1 & 30 & 1.7 & 118 & 12.5 & 124 & 33.0 & - & - & Flexural failure \\
\hline $\mathrm{B} 2$ & 32 & 1.4 & 130 & 8.5 & 160 & 20.5 & 1.03 & 29 & Shear failure \\
\hline B3 & 30 & 1.3 & 125 & 11.5 & 138 & 30.0 & 1.08 & 11 & Shear-flexural failure \\
\hline $\begin{array}{l}\text { Note: } P_{c r} \\
P_{Y}: \text { Steel } \\
P_{U}: \text { Steel } \\
\varepsilon_{u}: \text { Maxir }\end{array}$ & $\begin{array}{l}\text { Crackin } \\
\text { oars yiel } \\
\text { ars ulti } \\
\text { um tens }\end{array}$ & $\begin{array}{l}\text { load; } \\
\text { ng Load } \\
\text { ate failu } \\
\text { strain i }\end{array}$ & $\begin{array}{l}\text { load; } \\
\text { FRP a }\end{array}$ & & \multicolumn{5}{|c|}{$\begin{array}{l}\Delta_{c r}: \text { Midspan deflection at cracking load; } \\
\Delta_{y}: \text { Midspan deflection at yielding load; } \\
\Delta_{u}: \text { Midspan deflection at failure; }\end{array}$} \\
\hline
\end{tabular}

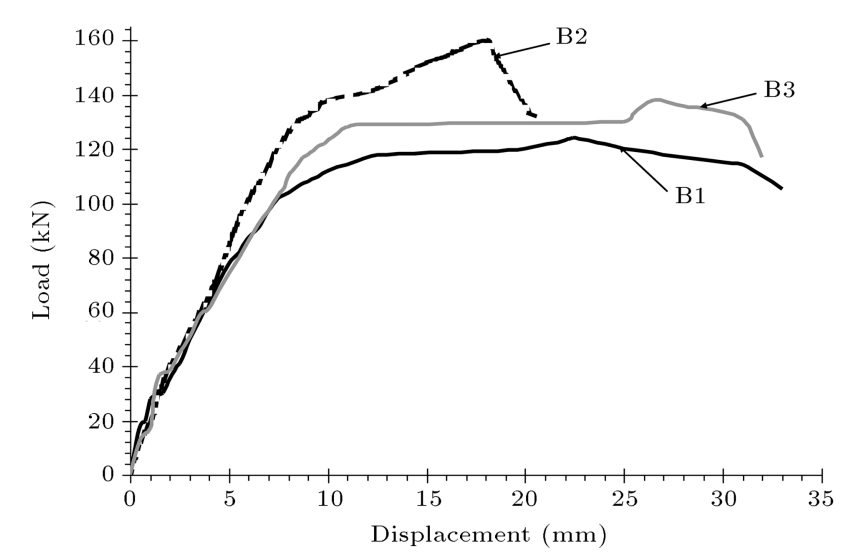

Figure 7. Load-midspan deflection behavior of flexural beams.

lower level, and the test stopped. Using NSM MMFRP bars resulted in a significant reduction in the crack widths and an increase in the quantity and propagation of new cracks in the strengthened beams, compared to control beam.
Beam B3 provided an insignificant increase in stiffness and strength due to early debonding observed at both ends of the MMFRP bars (Figure 8(d) and (e)). This indicated that the MMFRP bars anchorage in the concrete flange of the beam had a negligible effect on the ultimate load carrying the beam capacity. Beams B2 and B3, in comparison to the control beam, with embedment lengths of 1500, 900, and $450 \mathrm{~mm}$, had 29 and 11 percent increase in the ultimate strength, respectively. The significant increase in the ultimate load carrying capacity of beam B2, when compared to beam B3, was due to the longer embedment length of MMFRP bars used in this case. In general, higher elasticity modulus of MMFRP bars leads to a lower deflection and restrained propagation of flexural cracks resulting from deeper penetration into the section in strengthened beams, in comparison with control beam. This indicates an improvement in flexural stiffness and a reduction in ultimate deflections. The difference of flexural stiffness between beams B2 (with more embedment length of MMFRP bars) and B3 was more 
Table 6. Ductility index and curvature of flexural beams.

\begin{tabular}{ccccccc}
\hline Beam & $\begin{array}{c}\boldsymbol{\phi}_{\boldsymbol{y}} \\
\left(\mathbf{m m}^{-\mathbf{1}}\right)\end{array}$ & $\begin{array}{c}\boldsymbol{\phi}_{\boldsymbol{u}} \\
\left(\mathbf{m m}^{-\mathbf{1}}\right)\end{array}$ & $\boldsymbol{\mu}=\frac{\phi_{\boldsymbol{u}}}{\phi_{\boldsymbol{y}}}$ & $\begin{array}{c}\boldsymbol{\Delta}_{\boldsymbol{y}} \\
(\mathbf{m m})\end{array}$ & $\begin{array}{c}\boldsymbol{\Delta}_{\boldsymbol{u}} \\
(\mathbf{m m})\end{array}$ & $\boldsymbol{\mu}=\frac{\mathbf{\Delta}_{\boldsymbol{u}}}{\boldsymbol{\Delta}_{\boldsymbol{y}}}$ \\
\hline B1 & 0.0021 & 0.0084 & 4.00 & 12.5 & 33 & 2.64 \\
B2 & 0.0026 & 0.0075 & 2.88 & 8.5 & 20.5 & 2.41 \\
B3 & 0.0022 & 0.0073 & 3.30 & 11.5 & 30 & 2.61 \\
\hline
\end{tabular}

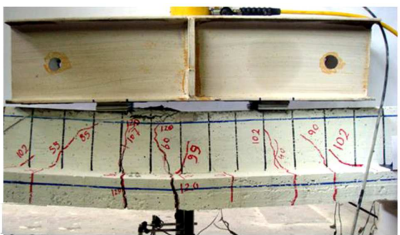

(a)

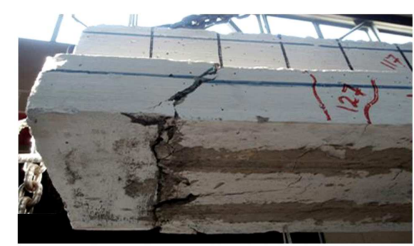

(c)

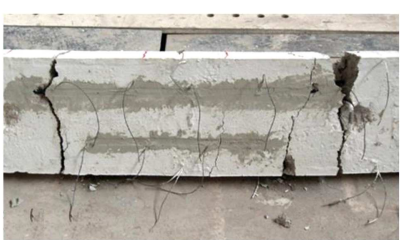

(e)

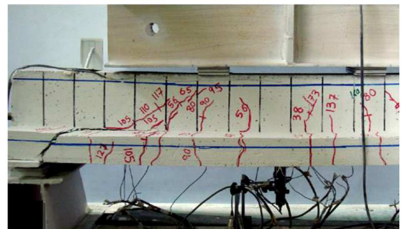

(b)

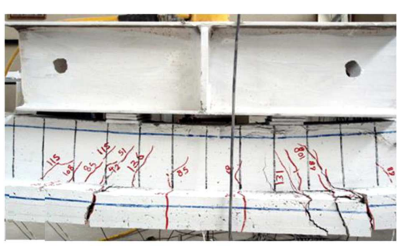

(d)

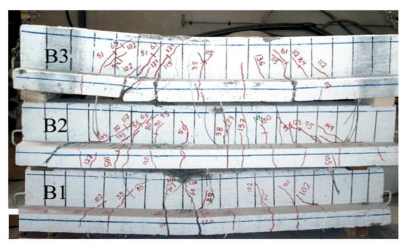

(f)
Figure 8. The failure modes of flexural strengthened beams with NSM bars: (a) Flexural failure of beam B1, (b) shear failure of beam B2, (c) concrete cover separation failure mode of beam B2, (d) flexural-shear failure of beam B3, (e) concrete cover separation failure mode of beam B3, and (f) comparison of crack patterns of flexural beams.

conspicuous; beam B2 increased up to ultimate load with the steeper slope; however, beam B3 behaved similar to control beam with smaller deflections. The failure mode of the beam can be supposed as shearflexural failure, as shown in Figure 8(d) with the crack patterns of flexural beams shown in Figure 8(f). For comparison purposes, the ductility indexes of beams are calculated using Eqs. (1) and (2) [8]:

$$
\begin{aligned}
& \mu=\frac{\Delta_{u}}{\Delta_{y}}, \\
& \mu=\frac{\phi_{u}}{\phi_{y}},
\end{aligned}
$$

where $\Delta_{u}$ and $\Delta_{y}$ are the ultimate and yield midspan deflections, respectively, and $\phi_{u}$ and $\phi_{y}$ are the ultimate and yield mid-span curvatures. The corresponding curvature of mid-span section is equal to $\phi=$ $\frac{\varepsilon_{c}}{x}$, where $\varepsilon_{c}$ and $x$ are the concrete strain and neutral axis depth, respectively. The neutral axis depth can be calculated at any level based on the strain values of concrete, top and bottom longitudinal reinforcements, and MMFRP bars, which are collected while testing, assumption of a linear distribution of strain through the depth of the mid-span section. Ductility results are summarized in Table 6 where it was observed that beams with NSM MMFRP bars experience a decrease in both ductility index and curvature relative to the control beams.

Moment-strain relationship for MMFRP bars is shown in Figure 9. The maximum strains of MMFRP bars obtained from beams B2 and B3, prior to debonding, were 1.03 and 1.08 percent, respectively, indicating that the MMFRP bars tensile strength proper utilization was achieved (Figure $9(\mathrm{a})$ and (b)). For beams B3 where the MMFRP bars were hooked at two ends, debonding of the NSM MMFRP bars occurred at an early stage and the bars anchorage did not provide more increase in the maximum tensile stress in the MMFRP bars, especially for the bar with an embedment length of $450 \mathrm{~mm}$ (Figure 9(c)).

\subsection{Shear beams}

The load-deflection behavior of the shear beams and the summarized results are shown in Figure 10 and Table 7 , respectively. Prior to the ultimate load, the behavior among all beams is almost similar, indicating that the stiffness of the beams is not significantly affected by shear MMFRP bars. As reported in Table 7, strengthened beams S2 and S3 experienced a significant increase in load carrying capacity over the control beam, ranging from $33 \%$ to $47 \%$, respectively. Beam S3, with inclined NSM reinforcement, had more effect on the ultimate load capacity increase when compared to beam S2, with vertical NSM reinforcement. It was probably due to the longer embedment length of inclined MMFRP bars. For a given load, the inclined bars with longer lengths can transfer more shear stresses via higher bond length. Moreover, with constant spacing of the MMNSM bars along the longitudinal axis of the beams, the vertical spacing among the bars in inclined bars is shorter than that in vertical bars, thus forming new cracks involving more bars at the same time, probably delaying the initiation and propagation of the cracks.

During the test, the control beam, S1, behaved as a conventional shear beam, and diagonal shear cracks initiated at the center of both shear spans at 


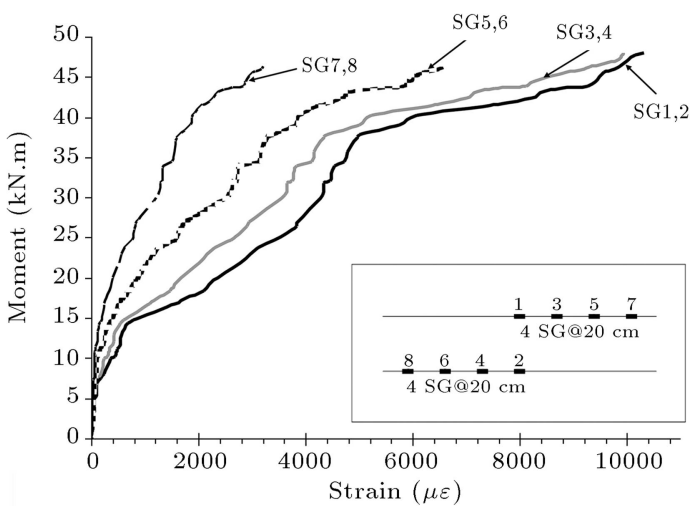

(a)

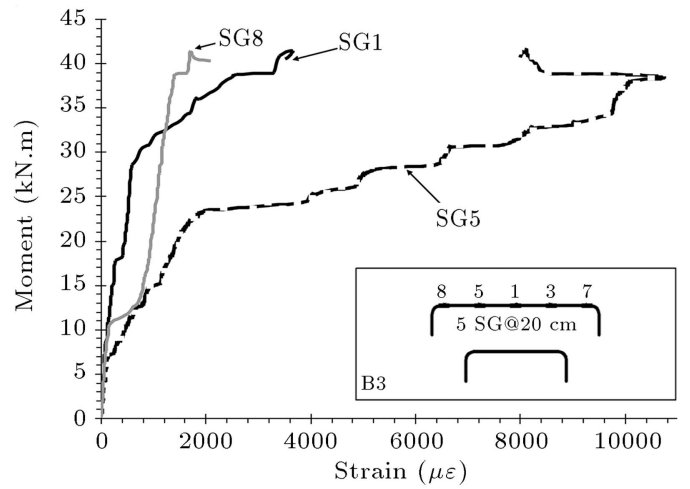

(b)

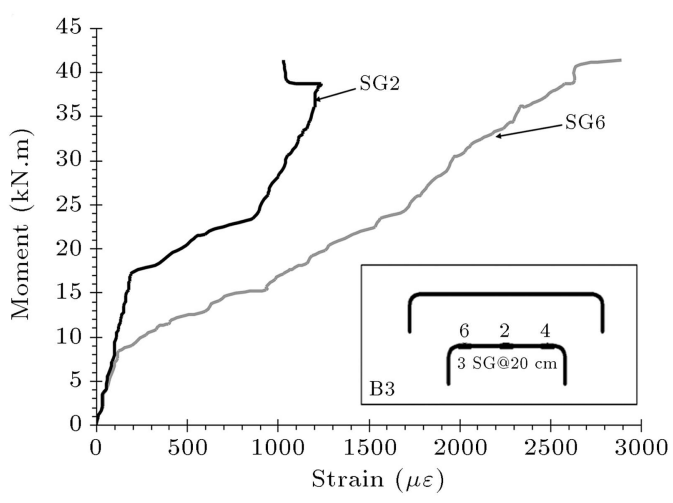

(c)

Figure 9. Strains in MMFRP bars in flexural beams: (a) Strains in beam B2, (b) strains of the longer bar of beam, and (c) strains of the shorter bar of beam B3.

Table 7. Experimental results of shear beams.

\begin{tabular}{|c|c|c|c|c|c|c|c|}
\hline Beam & $\begin{array}{c}P_{c r} \\
(\mathbf{k N})\end{array}$ & $\begin{array}{c}\Delta_{c r} \\
(\mathbf{m m})\end{array}$ & $\begin{array}{c}P_{U} \\
(\mathrm{kN})\end{array}$ & $\begin{array}{c}\Delta_{u} \\
(\mathbf{m m})\end{array}$ & $\begin{array}{c}\varepsilon_{u} \\
(\%)\end{array}$ & $\begin{array}{c}\text { Increase } \\
\text { in } P_{U} \\
(\%)\end{array}$ & Failure mode \\
\hline S1 & 30 & 1.1 & 104 & 9.5 & - & - & Shear failure \\
\hline $\mathrm{S} 2$ & 30 & 1.5 & 138 & 11.0 & 0.44 & 33 & Shear-flexural failure \\
\hline S3 & 30 & 1.6 & 153 & 16.0 & 0.53 & 47 & Flexural failure \\
\hline
\end{tabular}

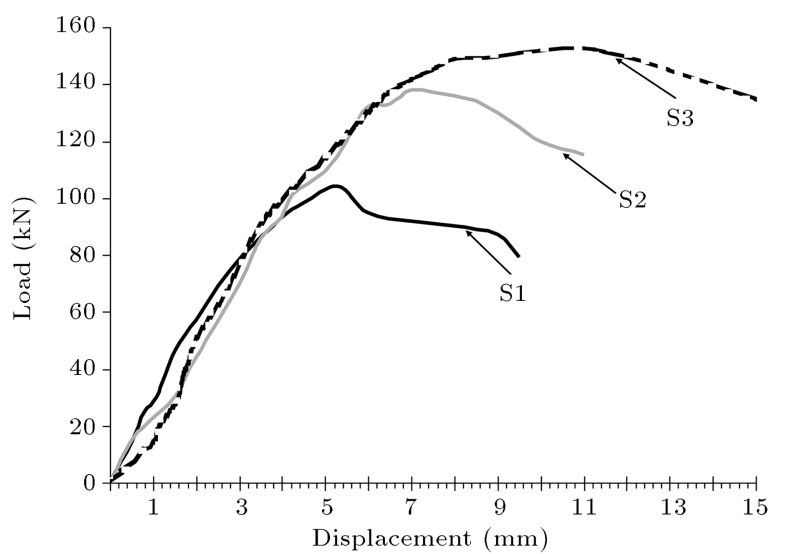

Figure 10. Load-midspan deflection behavior of shear beams. about mid-height of the beam. As the load increased, these cracks propagated until reaching the adjacent support and loading point, and more shear cracks were created within the shear span. These cracks widened and propagated until failure of beam occurred, as shown in Figure 11(a). The stirrup crossing the shear failure crack ruptured and the longitudinal tensile reinforcement did not yield. The angle of shear cracks to the longitudinal axis of the beam was close to $24^{\circ}$ (Figure 12(a)). In beam S2, with vertical NSM reinforcement, cracks normally started at the bottom of the beam as flexural cracks and propagated until the mid-height of the beam adjacent to the maximum moment region. As the load increased, more shearflexural cracks appeared and the diagonal shear cracks 


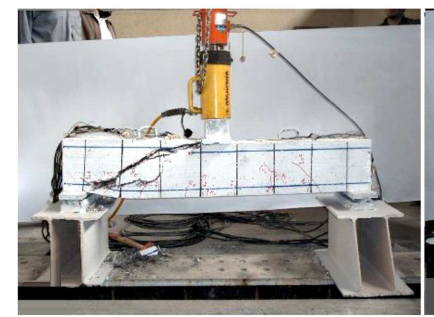

(a)

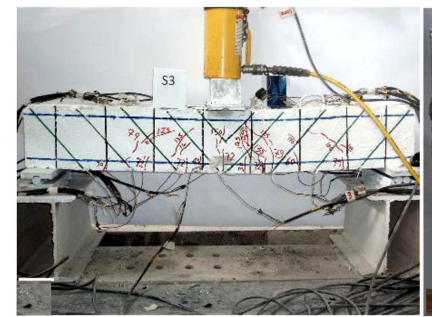

(c)

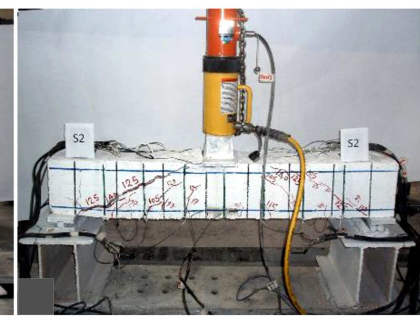

(b)

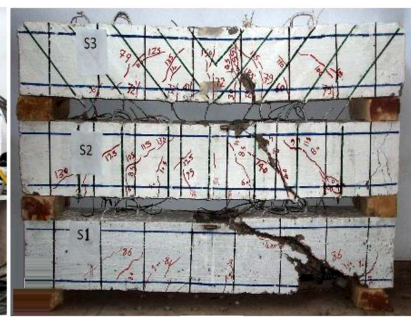

(d)
Figure 11. The failure modes of shear strengthened beams with NSM bars: (a) Shear failure of beam S1, (b) shear- flexural failure of beam S2, (c) flexural failure of beam S3, and (d) comparison of crack patterns of shear beams.

became gradually visible in the shear spans. These cracks spread and maintained a diagonal direction until reaching the adjacent support and applied load. These cracks widened until shear failure of beam occurred at one of the beam shear spans (Figure 11(b)), at an angle about $27^{\circ}$ to the longitudinal axis of the beam (Figure 12(b)). It is important to note that shear failure which occurred in this beam was not as brittle as the one observed in the control beam. As shown in Figure 12(b), close to failure of the beam, shear-flexural cracks spread over the shear spans; thus, the beam failure can be considered as shear-flexural failure.

As shown in Figure 11(c), in beam S3, with inclined NSM reinforcement, cracks started approximately vertically adjacent to the maximum moment region at the bottom of the beam as flexural cracks and spread towards the mid-height of the beam. As the load increased, more inclined shear-flexural cracks became gradually visible. Thereafter, cracks between the two NSM bars near the point of applied load gradually spread up to the loading point. Finally, flexural failure occurred in the maximum moment region by widening vertical cracks, and then beams failed due to yielding of tensile reinforcements and crushing of concrete. In this beam, a few cracks were visible on the side surfaces of the beam in the shear spans. The angle of cracks at failure was close to $70^{\circ}$ (Figure $12(\mathrm{c})$ ).

The crack patterns of shear beams are shown in Figure 11(d). In general, using NSM MMFRP reinforcement increased the cracks' quantity and propagation, reduced the crack widths, and delayed formation of new cracks in the strengthened beams, compared to control beam. The comparison of crack patterns in strengthened beams indicated that beam S3, with inclined NSM reinforcement, became more effective than beam S2, with vertical NSM reinforcement. This can again be explained by the longer embedment length of inclined MMFRP bars, probably delaying the early formation, and propagation of internal new cracks. Even though no visible debonding was observed in these tests, based on results of shear tests reported in previous investigations, the end anchorage of NSM bars had a significant effect on capacity and, particularly, on ductility of shear strengthened beams [14].

Figure 13 shows the shear-strain relationship of MMFRP bars of the strengthened beams. In strengthened beams, FRP strains became activated after the first shear crack. Once the concrete in the shear region cracked, the shear force was transferred to the MMFRP bars, and a rapid increase in strain in the MMFRP bars was observed. Strains in NSM MMFRP reinforcement increased until failure load, indicating that no debonding occurred. Due to constant shear load in shear spans, the relative position of the strain gages and major cracks exerted effects on maximum strains in MMFRP bars. For instance, in beam S2, the maximum strains were measured in the middle of the second MMFRP bar after the support, close to diagonal shear-flexural cracks in the middle of the shear span (Figure 13(a)). In beam S3, the maximum strains were measured at the middle of the third MMFRP bar after the support, close to flexural cracks under the point of applied load (see

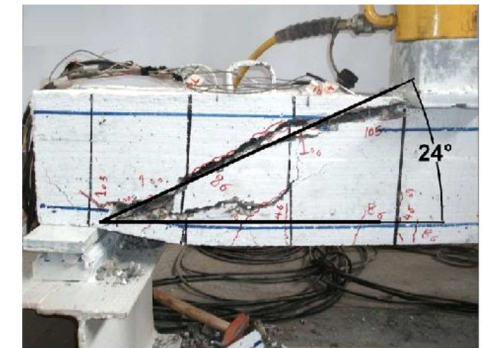

(a)

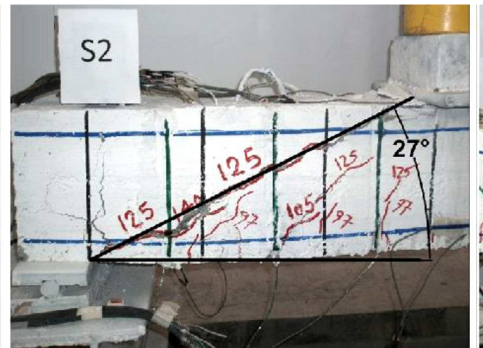

(b)

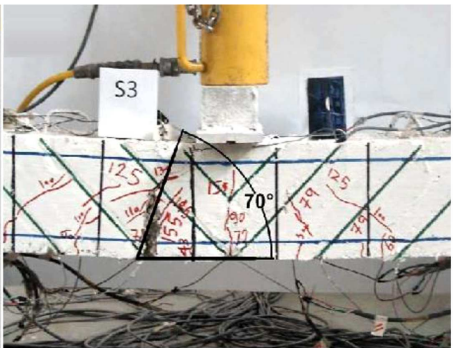

(c)

Figure 12. Angle of the cracks to the longitudinal axis of shear beams: (a) Beam S1, (b) beam S2, and (c) beam S3. 


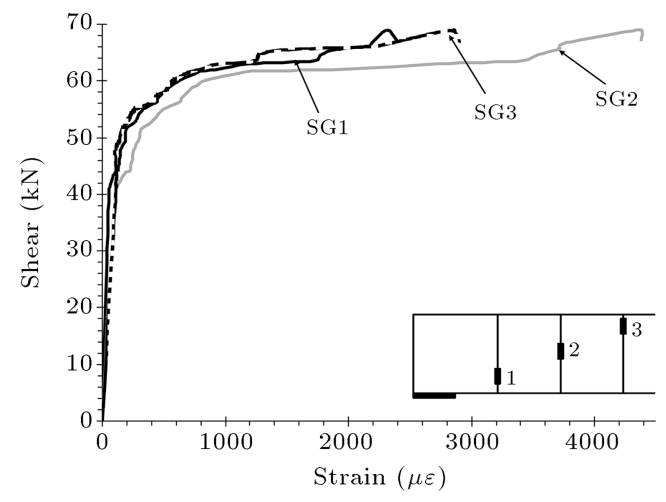

(a)

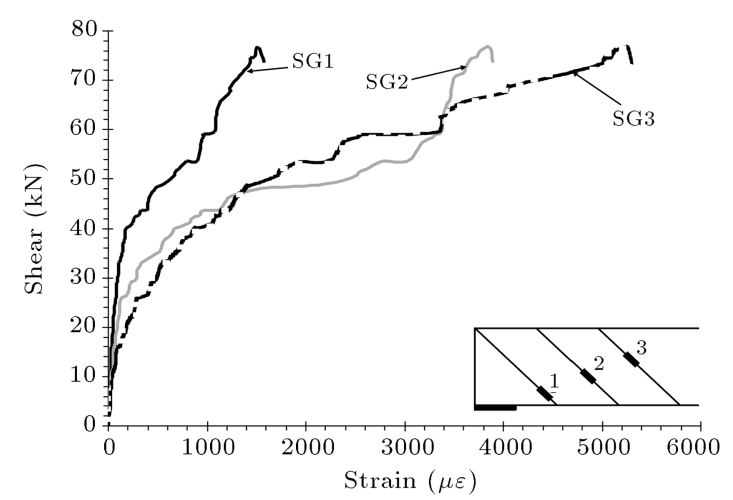

(b)

Figure 13. Strains in MMFRP bars in shear beams: (a) Strains in beam S2, and (b) strains in beam S3.

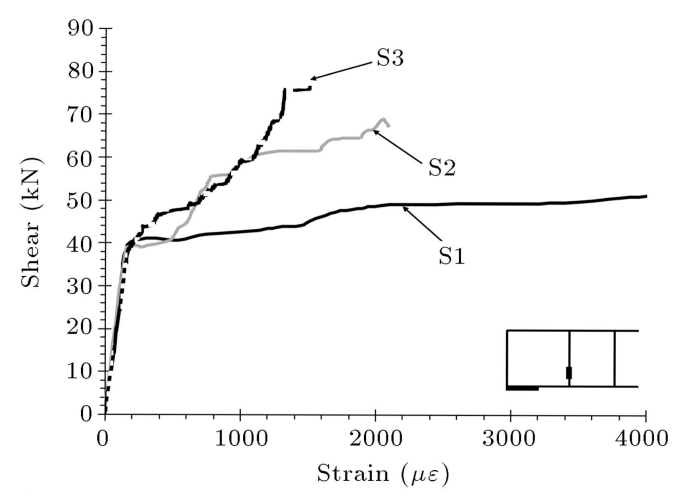

(a)

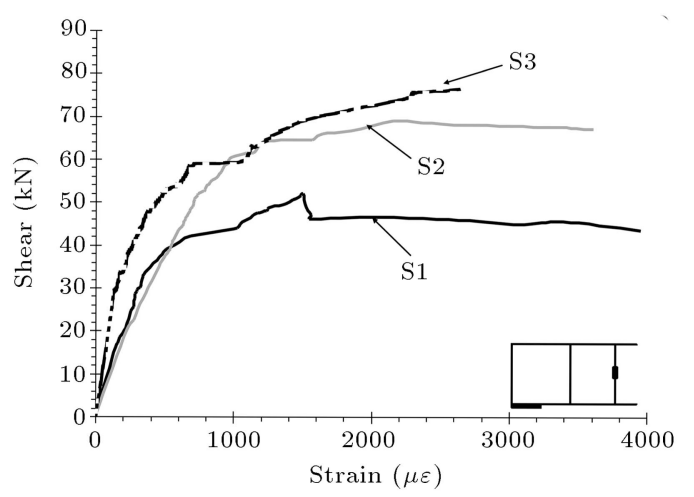

(b)

Figure 14. Load versus strains in steel stirrups in the shear beams: (a) Strains in the first steel stirrup after the support, and (b) strains in the second steel stirrup after the support.

Figure 13(b)). The maximum strains at the failure load for beams $\mathrm{S} 2$ and $\mathrm{S} 3$ were recorded as 0.44 and 0.53 percent, respectively, indicating that the inclined NSM reinforcement became more effective than vertical NSM reinforcement.

Figure 14 illustrates the shear-strain curves obtained from the strain gages attached to the first and second steel stirrups following the support in the shear beams. Comparison of the obtained stains of the first and second steel stirrup in strengthened beams with control beam indicated that the cracks in the shear span of strengthened beams were less than those in control beam due to presence of the NSM reinforcement and hence the stirrups close to the support had less strains but the maximum strains measured at the second stirrup close to cracks in the middle of the shear span were more than those measured at the first stirrup after the support at the end of test at higher level of loads. As shown in Figure 14(a) and (b), the maximum strains measured at the first and second steel stirrups after the support in beam S3 were smaller than those in beam S2, indicating that more shear forces were transferred to the MMFRP bars in beam S3. Therefore, inclined NSM bars had more effect on absorption of shear forces than vertical NSM bars.

\section{Numerical model}

ANSYS Finite-Element package [19] was implemented to model the experimental specimens and to present some noticeable advantages and disadvantages of shear beams, considering two major approaches: the discrete crack approach and the smeared crack approach, representing cracks in concrete structures [20]. The smeared crack approach models cracks in a smeared manner by applying an equivalent theory of continuum mechanics, while the discrete crack approach models a crack discretely as a geometrical entity. The smeared crack approach has been widely used because of its simplicity and availability in commercial FEA ANSYS software [19,21], adopting an appropriate material model to define the post-cracking tensile behavior of concrete [21]. The bond behavior of the concrete between both external FRP reinforcement and internal steel reinforcement may also play a significant role [22]. Chen proposed an advanced FE model for RC beams strengthened in shear with externally bonded FRP that takes into account an appropriate material model to define the post-cracking tensile behavior of concrete as well as the interfacial behavior of FRP and steel reinforcement [23]. Developing such advanced issues 
requires more efforts, and using simplified assumptions in FE analysis by commercial software is still popular [24-27].

Three types of elements were adopted in the FE modelling of experimental shear beams conducted in this paper. Solid65 that is defined by eight nodes with three degrees of freedom at each node, namely translations in nodal $x, y$, and $z$ directions, is widely used for 3D modelling of solids with or without rebars. This solid element is capable of modelling cracks in tension and crushing in compression and is utilized to model the concrete. The 3D spar Link 8 element is a uniaxial tension-compression element with three degrees of freedom at each node, namely translations in nodal $x, y$, and $z$ directions, and is used for modelling both longitudinal and transverse steel bars in the concrete beams. The modelling of steel reinforcement was carried out by the use of discrete model in which rebar elements were connected to concrete mesh nodes. NSM FRP bars are working in tension-only mode; therefore, LINK10 was used for FRP modeling. LINK10 is a 3D spar element having the unique feature of a bilinear stiffness matrix resulting in a uniaxial tension-only (or compression-only) element. For MMFRP elements, the tension-only option was used, and the stiffness was removed if the element went into compression. The perfect bond was assumed in this work; therefore, the slip between concrete and either MMFRP bars was assumed as zero in FE model.

\subsection{Material properties}

Compressed concrete was considered to be linear elastic up to about $0.3 f^{\prime} c$, where $f^{\prime} c$ is cylinder compressive strength; beyond that point, it exhibits strain hardening followed by a post-peak softening curve. The model requires a biaxial state for concrete, for which the theoretical failure surface proposed by William and Warnke [28] was considered, as shown in Figure 15(a). Therefore, numerical expressions were used to construct the uniaxial compressive and tensile stressstrain curve as shown in Figure 15(b) and (c) [29]. In the William-Warnke concrete model, $\sigma_{x p}$ and $\sigma_{y p}$ are the most significant non-zero principal stresses in $x$ and $y$ directions, respectively. The mode of failure is a function of the sign of principal stress in $z$ direction $\left(\sigma_{z p}\right)$. For all shear specimens, $f^{\prime} c$ and concrete rupture modulus, $f_{r}$, and Poisson's ratio, $v$, were $22 \mathrm{MPa}, 2.6 \mathrm{MPa}$, and 0.2 , respectively. A linear elastic isotropic constitutive relation is assumed for the FRP composite with modules of elasticity of $235 \mathrm{GPa}$. Taking advantage of symmetry about both the midspan and mid-width planes, a quarter of the beam was included in the FE model. Total applied displacement was divided into a series of load steps.

\subsection{Results and discussion}

Figure 16 shows and compares the load versus midspan deflection curves of shear beams obtained from numerical and experimental results, as shown in Table 8. Numerical models predicted reasonable values for maximum load bearing capacity of beams as well as shape of the general load deflection curves; however, failure modes were not clear to achieve. The crack patterns in $\mathrm{S} 2$ and $\mathrm{S} 3$ beams at failure, obtained from numerical and experimental studies, are compared and shown in Figure 16. Strain magnitudes in mesh elements revealed the maximum widening areas on shear failure. Figure 17 depicts areas with the largest strains

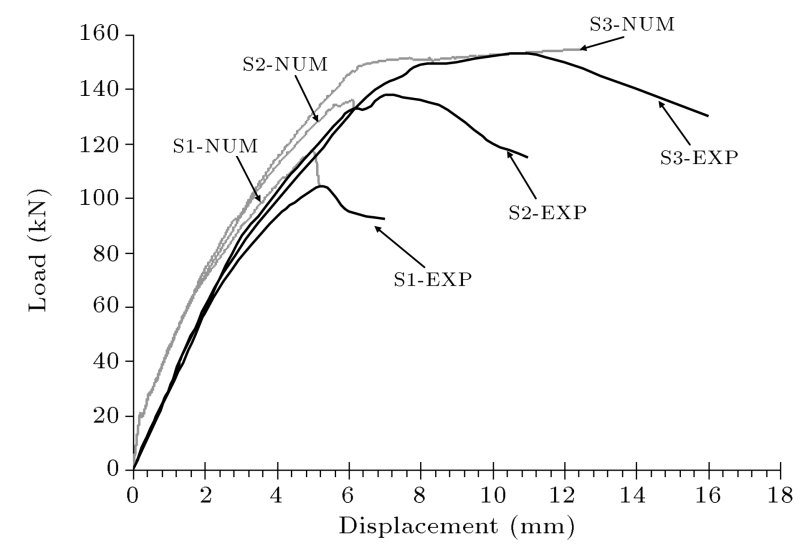

Figure 16. Experimental versus numerical load-deflection curves for shear specimens.

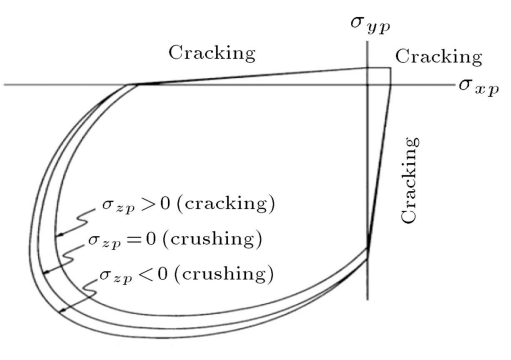

(a)

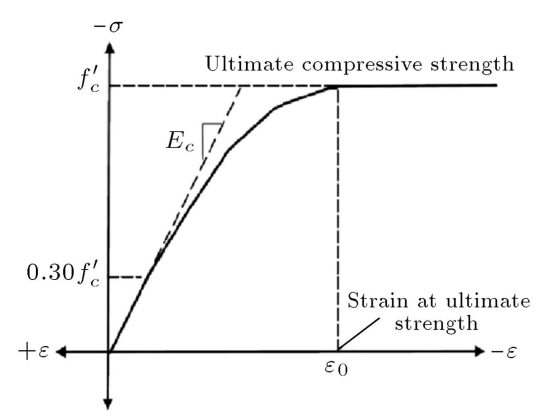

(b)

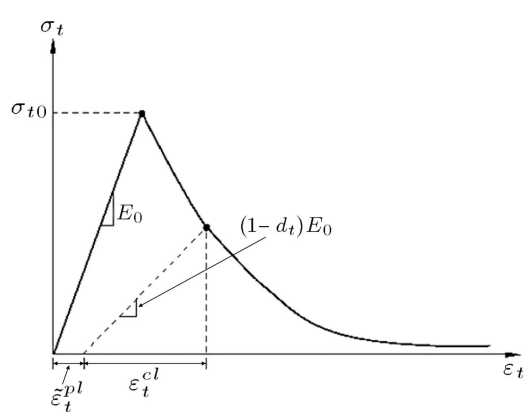

(c)

Figure 15. Constitutive laws of concrete: (a) Biaxial state, (b) compression uniaxial state, and (c) tensile stress-strain curve. 


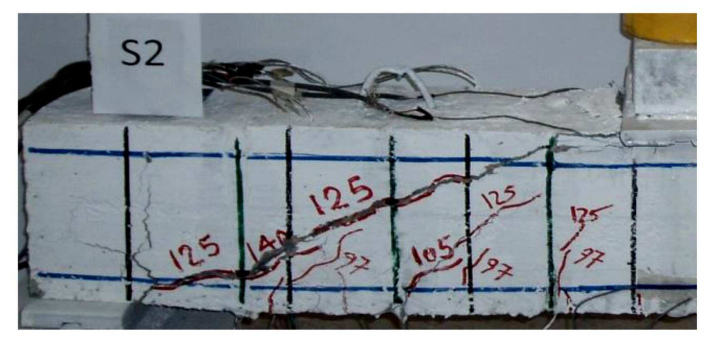

S2 specimen-experimental

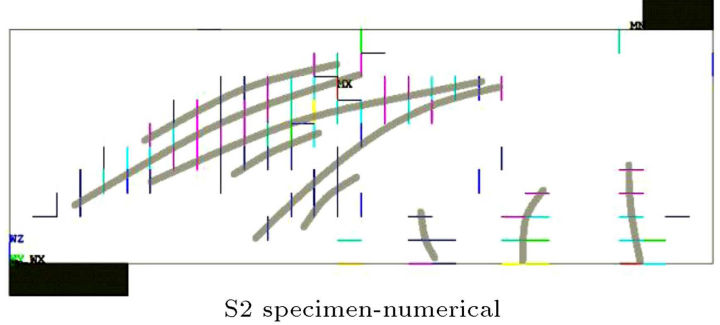

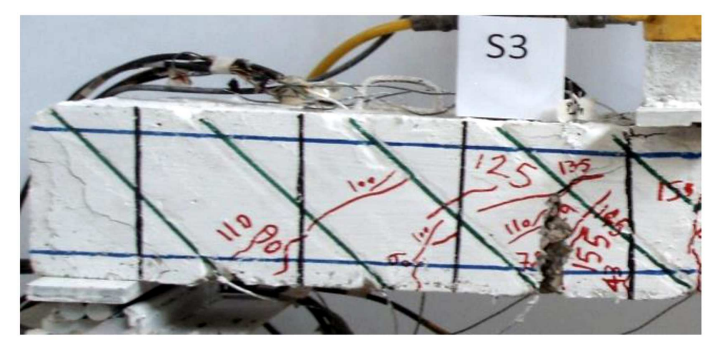

S3 specimen-experimental

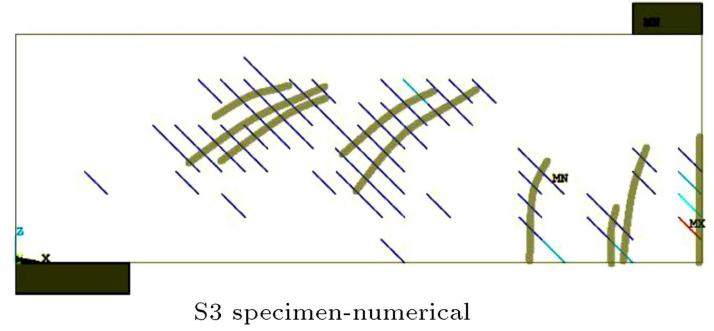

Figure 17. Comparison of crack patterns in numerical and experimental tests.

Table 8. Comparison of numerical and experimental results; maximum applied load.

\begin{tabular}{cccc}
\hline \multirow{2}{*}{ Specimen } & \multicolumn{3}{c}{ Maximum applied load $(\mathbf{k N})$} \\
\cline { 2 - 4 } & Numerical & Experimental & $\begin{array}{c}\text { Load ratio } \\
\left(\boldsymbol{N}_{\text {num }} / \boldsymbol{E}_{\text {exp }}\right)\end{array}$ \\
\hline S1 & 117.15 & 104 & 1.13 \\
S2 & 136.15 & 138 & 0.99 \\
S3 & 154.8 & 153 & 1.01 \\
\hline
\end{tabular}

Table 9. Comparison of numerical and experimental results; maximum strain value in MMFRP.

\begin{tabular}{|c|c|c|c|c|c|c|}
\hline \multirow{3}{*}{$\begin{array}{c}\text { Strain } \\
\text { gauge no. }\end{array}$} & \multicolumn{4}{|c|}{ Maximum strain value $\left(\times 10^{-6}\right)$} & \multirow{2}{*}{\multicolumn{2}{|c|}{$\begin{array}{l}\text { Numerical/ } \\
\text { experimental }\end{array}$}} \\
\hline & \multicolumn{2}{|r|}{ S2 } & \multicolumn{2}{|c|}{ S3 } & & \\
\hline & Numerical & Experimental & Numerical & Experimental & $\mathrm{S} 2$ & S3 \\
\hline 1 & 2146 & 2400 & 2340 & 1590 & 0.89 & 1.47 \\
\hline 2 & 3179 & 4387 & 3441 & 3900 & 0.72 & 0.88 \\
\hline 3 & 1996 & 2900 & 2038 & 5300 & 0.69 & 0.38 \\
\hline
\end{tabular}

on beams. For S2 and S3 specimens, perpendicular and inclined meshes were implemented, respectively. The numerical model presented a crack band, whereas, in experimental condition, an individual crack appeared at failure. Moreover, the location of maximum crack width was not identical in experimental tests and FE models.

The maximum strain values in MMFRP bars, calculated by the FEA (from points that were very close to the real position of strain gauge at the experimental specimen) and obtained from experimental results, are compared in Table 9 and depicted in Figure 18. Good agreement exists between numerical and experimental findings in Beam S3; however, unfavorable agreement exists between numerical and experimental findings in Beam S2. The FEA modeling approach generally predicted the overall load-displacement response of the shear-strengthened beams with reasonable accuracy; however, this approach was unable to predict the failure modes accurately. Other researchers have reported some of the above mentioned results $[30,31]$.

\section{Conclusions}

In this research, the behavior of RC beams strengthened in shear and flexure using NSM technique with innovative MMFRP bars was investigated by experimental and numerical approaches. The following conclusions can be drawn from the outcomes of this research:

- The beams strengthened in flexure with NSM MMFRP bars revealed an improvement in flexural stiffness and bending capacity up to 29 percent and an 


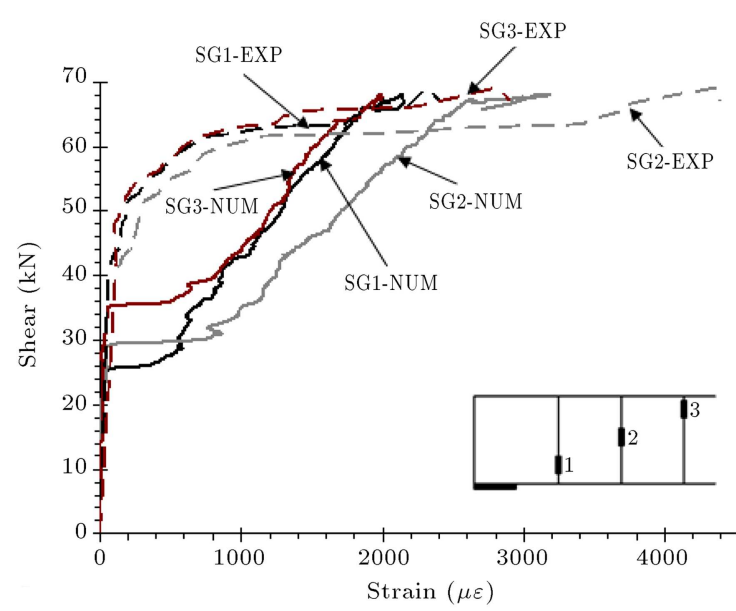

(a)

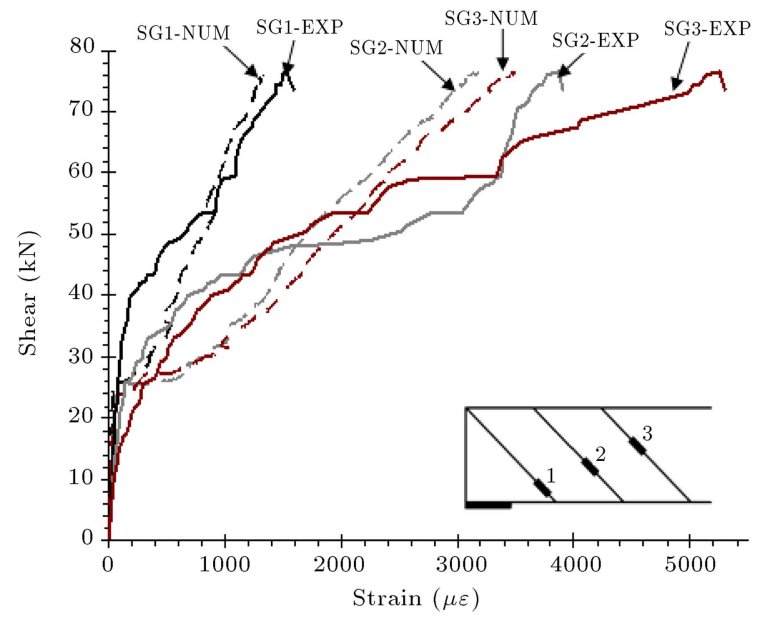

(b)

Figure 18. Shear load-strain distribution curves in MMFRP rods: (a) Beam S2, and (b) beam S3.

increase in quantity and propagation of new cracks over the control beam;

- Maximum strains of MMFRP bars obtained prior to debonding were 1.03 and 1.08 percent, indicating that proper utilization of the tensile strength of the MMFRP bars was achieved;

- The use of MMFRP bars, particularly with inclined situation, increased the shear capacity of the deficient beams up to 47 percent over the control beam;

- The maximum strains of vertical and inclined bars at the failure were recorded up to 0.44 and 0.53 percent, indicating that inclined MMFRP bars became more effective than vertical bars;

- Failure shear mode of the beams strengthened with these bars was not as brittle as the control beam, changing from shear failure in control beam to shearflexural or flexural failure in strengthened beams;

- The proposed bars significantly enhanced the ductility of the shear specimens;

- The FEA modelling approach can predict the overall load-displacement response of the shearstrengthened beams with reasonable accuracy, yet was unable to predict the failure modes accurately.

\section{References}

1. Benmokrane, B. and Masmoudi, R. "FRP C-bar as reinforcing rod for concrete structure", Proceedings of the International Conference on FRP Composites in Advanced Composite Materials in Bridges and Structures, Montreal, pp. 181-188 (1996).

2. Behzard, P., Sharbatdar, M.K., and Kheyroddin, A. "A different NSM FRP technique for strengthening of RC two-way slabs with low clear cover thickness", Scientia Iranica A, 23(2), pp. 520-34 (2016).
3. Sattarifard, A.R., Sharbatdar, M.K., and Dalvand, A. "RC connections strengthened with FRP sheets using grooves on the surface", International Journal of Civil Engineering, 13(4A), pp. 432-43 (2015).

4. El-Hacha, R. and Rizkalla, SH. "Near surface mounted fiber reinforced polymer reinforcements for flexural strengthening of concrete structures", ACI Structural Journal, 101(5), pp. 717-26 (2004).

5. Asplund, S.O. "Strengthening bridge slabs with grouted reinforcement", ACI Structural Journal, 45, pp. 397-406 (1994).

6. American Concrete Institute Technical Committee 440 "Guide for the design and construction of externally bonded FRP systems for strengthening concrete structure", ACI 440.2R-08 (2008).

7. De Lorenzis, L. and Teng, G.J. "Near surface mounted FRP reinforcement: An emerging technique for strengthening structures", Journal of Composite Part B, 38, pp. 119-143 (2007).

8. De Lorenzis, L. and Nanni, A. "Shear strengthening of reinforced concrete beams with near surface mounted FRP rods", ACI Structural Journal, 98(1), pp. 60-68 (2001).

9. Etman, E. "External bonded shear reinforcement for T-section beams", Structural Concrete, 12(3), pp. 137220 (2011).

10. Rizzo, A. and De Lorenzis, L. "Behavior and capacity of RC beams strengthened in shear with NSM FRP reinforcement", Construction \& Building Material, pp. 1555-1567 (2009).

11. Anwarul Islam, A.K.M. "Effective methods of using CFRP bars in shear strengthening of concrete girders", Engineering Structural, pp. 709-14 (2009).

12. Lim, D.H. "Shear behavior of RC beams strengthened with NSM and EB CFRP strip", Magazine of Concrete Research, 62(3), pp. 211-220 (2010).

13. Atalay, H.M., Akpinar, E., Hakan Erdogan, H., and Vulaş, Y.Z. "Shear strengthening of reinforced concrete 
T-beams with fully or partially bonded fibre-reinforced polymer composites", Structural Concrete, 15(2), pp. 115-276 (2014).

14. Jalali, M., Sharbatdar, M.K., Chen, J.F., and Jandaghi Alaee, F. "Shear strengthening of RC beams using innovative manually made NSM FRP bars", Construction \& Building Material, pp. 990-1000 (2012).

15. Esfandi Sarafraz, M. and Danesh, F. "New technique for flexural strengthening of RC columns with NSM FRP bars", Magazine of Concrete Research, 64(2), pp. 151-161 (2012).

16. Micelli, F. and De Lorenzis, L. "Near-surface mounted flexural strengthening of reinforced concrete beams with low concrete strength", Magazine of Concrete Research, 166(5), pp. 295-303 (2013).

17. Sharbatdar, M.K. "Concrete columns and beams reinforced with FRP bars and grids under monotonic and reversed cyclic loading", PhD Thesis, Department of Civil Engineering, University of Ottawa, Canada (2003).

18. CAN/CSA-S6-02, "Design and construction of building components with fibre reinforced polymers", Canadian Standards Association, Rexdale, Canada (2002).

19. ANSYS, FEA, "Software and User's Manual" (2003).

20. American Concrete Institute Technical committee 446 "Finite element analysis of fracture in concrete structures: State-of-the-Art", ACI 446.3R-97.

21. ABAQUS "FEA software and user's manual" (2004).

22. Godat, A., Neale, K.W. and Labossiere, P. "Numerical modeling of FRP shear strengthened reinforced concrete beams", ASCE, Journal of Composite for Construction, pp. 640-49 (2007).

23. Chen, G.M., Chen, J.F., and Teng, J.G. "On the finite element modeling of RC beams shear strengthened with FRP", Construction \& Building Material, 32, pp. 13-26 (2010).

24. Elyasian, I., Abdoli, N., and Ronagh, H.R. "Evaluation of parameters effective in FRP shear strengthening of RC beams using FE method", Asian Journal Civil Engineering (Building and Housing), 7, pp. 249-57 (2006).

25. Kachlakev, D. "Finite element modeling of reinforced concrete structures strengthened with FRP laminates", Oregon Department of Transportation Research Group, Final Report, SPR 316 (2002).

26. Santhakumar, R., Chandrasekaran, E., and Dhanaraj, R. "Analysis of retrofitted reinforced concrete shear beams using carbon fiber composite", Journal Structural Engineering, 4, pp. 66-74 (2004).

27. Zhang, Z.C. and Hsu, C.T.T. "Shear strengthening of reinforced concrete beams using carbon-fiberreinforced polymer laminates", ASCE, Journal of Composite for Construction, pp. 158-69 (2005).
28. William, K.J. and Warnke, E.P. "Constitutive model for the tri-axial behavior of concrete", Proceedings of International Association for Bridge and Structural Engineering, Bergamo (Italy): ISMES (1975).

29. Desayi, P. and Krishnan, S. "Equation for the stressstrain curve of concrete", J. Am. Concr. Inst., pp. 345350 (1964).

30. Chen, G.M. "Behavior and strength of RC beams shear strengthened with externally bonded FRP reinforcement", PhD Thesis, Department of Civil and Structural Engineering, The Hong Kong Polytechnic University, Hong Kong, China (2010).

31. Rahimi, R. and Hutchinson, A. "Concrete beams strengthened with externally bonded FRP plates", ASCE Journal of Composite for Construction, pp. 4456 (2001).

\section{Biographies}

Mohammad Kazem Sharbatdar received his BSc degree in Civil Engineering from Sharif University of Technology, Tehran, Iran in 1989, MSc degree in Structural Engineering from Amirkabir University of Technology, Tehran, Iran in 1992, and PhD degree in Structural Engineering- Reinforced structures from Ottawa University, Ottawa, Canada in 2003. He is currently an Associate Professor in Faculty of Civil Engineering at Semnan University, Iran. He has published five books on Construction Management, Nanotechnology in Civil Engineering, Strengthening of Infrastructures with FRP materials, FRC slabs (in Persian). He has more than 21 years of teaching experience in several fields at both undergraduate and graduate courses. He has authored and coauthored more than 50 research papers. He has also more than 120 papers in national and international conferences, mainly related to the laboratory researches. He has 5 patents. He has also supervised numerous MS and $\mathrm{PhD}$ degree theses. His main research areas are retfotting of deficient RC structures, experimental application of HPFRCC composites for new structures and strengthening existing structures, advanced concrete technology, numerical and experimental research on hybrid connections.

Mostafa Jaberi received his BSc degree in Civil Engineering from Shahrud University in 2003. He was accepted for Structural Engineering in Faculty of Civil Engineering at Semnan University. He carried out his research thesis, titled "Shear strengthening of RC beams with FRP man-made bars at NSM method" under supervision of Dr. Sharbatdar and acquired excellent grade. His research achievements have been quite significant and has already published two conference papers and 1 patent. He is currently a professional engineer. 